\title{
Representaciones sobre migrantes en Argentina durante la presidencia de Cristina Fernández: ¿una posible alternativa al discurso dominante?
}

\section{Rocío Flax}

El presente artículo se inscribe en un proyecto de investigación que estudia las representaciones sociales que diferentes actoras sociales construyen sobre las migrantes en Argentina a partir del año 2003. En esta ocasión, analizamos cómo se elabora la identidad de las migrantes en el discurso institucional durante las presidencias de Cristina Fernández (2007-2015). En particular, analizamos la publicación realizada en el año 2011 por la Dirección Nacional de Migraciones denominada Nosotros, los que vinieron. Inscribimos nuestra investigación en el Análisis Crítico del Discurso, corriente que considera que cambios en los discursos pueden llevar aparejados cambios en las representaciones mentales, en las actitudes y los comportamientos de las personas.

Palabras claves: representaciones sociales, marcos conceptuales, migrantes, kirchnerismo.

Representations on migrants in Argentina during the presidency of Cristina Fernández: an alternative to dominant discourse? This paper presents part of a research project on social representations about migrants in Argentina since 2003, constructed by different social actors. On this occasion, we analyze the way in which migrants' identity is elaborated in the institutional discourse during the presidencies of Cristina Fernández (2007-2015). Analysis will focus on the publication made in 2011 by the National Directorate of Migrations called We, those who came. Our research adopts Critical Discourse Analysis (CDA) as main framework. This frame considers that changes in discourses can lead to changes in mental representations, attitudes and behaviors of people.

Keywords: social representations, conceptual frames, migrants, kirchnerism. 


\section{Introducción}

El presente artículo se inscribe en un proyecto de investigación que estudia las representaciones sociales que diferentes actoras ${ }^{1}$ sociales construyen sobre las migrantes en Argentina a partir del año 2003. En esta ocasión, investigamos cómo se elabora la identidad de las migrantes en el discurso institucional durante las presidencias de Cristina Fernández (2007-2015). En particular, seleccionamos para su análisis el libro editado en el año 2011 por la Dirección Nacional de Migraciones (DNM). ${ }^{2}$ Dicho libro se titula Nosotros, los que vinieron y recopila treinta y siete historias de vida de migrantes de diferentes partes del mundo. ${ }^{3}$ Las historias son el producto de entrevistas realizadas entre los años 2009 y 2011, reelaboradas en forma de narraciones que, en algunos fragmentos, habilitan la voz de las entrevistadas a través del discurso referido directo. ${ }^{4}$

Inscribimos nuestra investigación en el Análisis Crítico del Discurso (Fairclough 2014) y tomamos como ejes de análisis el relevamiento de las acciones sociales (van Leeuwen 2008) y los marcos conceptuales (Lakoff $2002,2010)$ que se asocian a las migrantes. En el siguiente apartado, desarrollamos tanto el marco teórico como las herramientas utilizadas para el análisis. En el apartado 3, realizamos una descripción del corpus seleccionado, mientras que, en el apartado 4 , procedemos a su análisis.

\section{Marco teórico y metodológico}

Para el Análisis Crítico del Discurso (ACD) (Fairclough 1992, 2000, 2005, 2014; van Leeuwen 2008), el término "discurso" refiere a cualquier uso del lenguaje entendido como una forma de práctica social, antes que como una actividad individual influenciada por variables situacionales. Desde esta perspectiva teórica, el análisis debe comenzar por un problema social para observar el funcionamiento de los discursos vinculados con dicha problemática y el papel que juegan en la producción y reproducción del poder.

Considerar al lenguaje una práctica social posee una serie de implicancias (Fairclough 1992, 2014). En primer lugar, supone que, además de ser un modo de representación -una forma de estructurar el conocimiento-, es una conducta a través de la cual las personas actúan sobre el mundo y sobre las otras. En segundo lugar, supone que el discurso establece una relación de interdependencia recíproca con otras prácticas y sirve no solo para reflejar identidades y relaciones sociales sino también para constituirlas. Por último, implica que hay una relación de condicio-

Lengua y migración / Language and Migration 12:2 (2020), 45-64

Edición impresa: ISSN 1889-5425. Edición en línea: ISSN 2660-7166. (C) Universidad de Alcalá 
namiento mutuo entre el lenguaje y la estructura social (como la hay entre cualquier práctica y la estructura social): la estructura es tanto una condición como un efecto del lenguaje.

Como dijimos, para el ACD, el discurso es socialmente constitutivo: construye sujetas sociales, relaciones sociales, sistemas de conocimiento y creencias. Por ello, su estudio se enfoca en estos efectos ideológicos constructivos. El ACD no se ocupa solamente de las relaciones de poder que establecen los discursos, sino también de cómo esas relaciones y luchas por el poder forman y transforman las prácticas discursivas de una sociedad o una institución. El análisis atiende al funcionamiento discursivo en la transformación creativa de ideologías y prácticas, así como en su funcionamiento para asegurar su reproducción (Fairclough 1992).

Por último, para esta corriente teórica, el método de análisis debe ser crítico. Las relaciones entre discurso y cambio social y cultural son típicamente opacas para las personas. El adjetivo "critico" supone mostrar las conexiones y las condiciones de posibilidad de los discursos que permanecen ocultas. En este sentido, es importante no mantener una imagen del cambio discursivo como unilineal y de arriba hacia abajo: existen luchas en la estructuración de los textos y las personas pueden resistirse o apropiarse de los cambios que se intentan imponer. Las aproximaciones críticas se diferencian de las no-críticas en tanto no solo describen las prácticas discursivas, sino que también muestran cómo el discurso es constituido por las relaciones de poder y por las ideologías, y exponen los efectos que tiene el discurso sobre las identidades sociales, las relaciones sociales y los sistemas de conocimiento y creencias.

Utilizamos como herramientas metodológicas, en primer lugar, la clasificación que realiza van Leeuwen (2008) de las formas de representar las acciones sociales y la teoría de los marcos conceptuales de Lakoff (2002, 2006, 2010), en segundo lugar. A continuación, desarrollamos ambas.

\subsection{La representación de acciones sociales}

En su libro New Tools for Critical Discourse Analysis, van Leeuwen (2008) elabora una clasificación para el estudio de las diversas formas en que se pueden representar las acciones de las actoras sociales en el discurso. Esta clasificación comienza con una primera separación entre acciones y reacciones. La acción social puede ser interpretada como material o como semiótica, es decir, como "haciendo" o "significando". La primera tiene un objetivo o efecto físico y la segunda, no. Sin embargo, los procesos semióticos pueden ser materializados utilizando, por ejemplo, una metáfora como "atacar".

La distinción entre acciones materiales transactivas -aquellas que poseen una actora y una afectada- y no transactivas -aquellas que solo 
poseen una actora o una afectada- es importante ya que diferencia qué actoras sociales y qué acciones pueden tener efecto en otras o en el mundo y cuáles no. La habilidad de afectar a otras requiere cierto poder y, cuanto mayor sea el poder, mayor la cantidad de metas que puede afectar la acción de una actora social.

Las acciones semióticas también pueden ser transactivas o no transactivas. Pueden estar representadas como una conducta o puede aparecer la afectada y/o el discurso referido. Las actoras con menos poder serán representadas en acciones semióticas no transactivas. Además, no es lo mismo si solo se menciona que realizaron un proceso verbal (hablar, decir, comentar), si se explicita el tema del proceso verbal (por ejemplo, "habló sobre el cambio climático") o si se cita lo que dijeron. Cuanta menor importancia se les otorga a las palabras de las actoras, se implica, en la representación, que poseen menor poder: esta sería la diferencia, por ejemplo, entre citar los dichos de una persona -de forma completa o nofrente a remitirse solamente al tema o tópico de la acción semiótica.

Por su parte, las reacciones refieren a las acciones vinculadas con el ámbito de lo mental. Según van Leeuwen (2008), las reacciones pueden ser una señal de carencia de poder: a medida que el poder de las actoras sociales decrece, aumenta la cantidad de reacciones emotivas que se les atribuyen. Las reacciones pueden pertenecer al campo semántico del deseo o el afecto, la cognición o la razón, o la percepción. Cuanto más poderosa sea la actora social, más probable que se le atribuyan reacciones racionales y no afectivas. No obstante, encontramos problemática la clasificación de ciertos procesos cognitivos o intelectuales ("aprender", "estudiar", "leer", incluso procesos como "entender" o "comprender" que, según los contextos, suponen una clara voluntad consciente) como meras reacciones al igual que las respuestas emocionales. Consideramos, en cambio, que podría agregarse una categoría especial para las acciones cognitivas, junto con las acciones materiales y semióticas. Así, la clasificación quedaría como se muestra en el siguiente cuadro:

\begin{tabular}{|l|l|l|}
\hline \multirow{4}{*}{ Acciones } & \multirow{3}{*}{ Transactivas } & Materiales \\
\cline { 3 - 3 } & & Semióticas \\
\cline { 3 - 3 } & Cognitivas \\
\hline \multirow{3}{*}{ No transactivas } & Materiales \\
\cline { 3 - 3 } & & Semióticas \\
\cline { 3 - 3 } & Cognitivas \\
\hline \multirow{2}{*}{ Reacciones } & \multirow{2}{*}{ No transactivas } & Percepción \\
\cline { 3 - 3 } & & Afecto y emoción \\
\hline
\end{tabular}

Cuadro 1. Formas de representar la acción social 


\subsection{Marcos conceptuales}

Según Lakoff $(2002,2006,2010)$, cada vez que una persona utiliza el lenguaje para hablar de algo, activa marcos conceptuales en asociación con ese tema; en general, esto se realiza de manera automática e inconsciente, por lo tanto, no es algo que pueda evitar y, en muchas ocasiones, sucede sin que las hablantes se den cuenta y/o puedan controlarlo. Los marcos se organizan en sistemas de conceptos que se activan en conjunto, aunque sea parcialmente, en el momento en que se activa el marco. Por ejemplo, la palabra "dinero" se encuentran asociada con un sistema de conceptos: ganar dinero, perder dinero, prestar dinero, banco, inversión, compra, venta, negocios, entre otras. Cuando se habla del tiempo en términos de dinero, estamos activando, al menos, una parte de dicho sistema ("perder el tiempo", "ganar tiempo", "invertir tiempo").

Cada vez que un marco conceptual se utiliza para hablar de cualquier tema -en nuestro ejemplo, del tiempo como dinero-, la asociación entre ese tema y ese marco se fortalece. Según Lakoff, las posibilidades de cambiar los marcos con los que las personas piensan o se refieren a un tema en particular son limitadas. Introducir una nueva manera de hablar requiere que sea comprensible para las interlocutoras y, para ello, debe tener sentido en términos del sistema existente de marcos. Además, sería necesaria una difusión suficiente entre la población, suficiente repetición y suficiente confianza en las mensajeras para que el nuevo marco sea aceptado y consolidado.

\subsubsection{Metáforas y categorías}

Los marcos conceptuales, en algunos casos, se pueden estructurar a partir de metáforas o categorías radiales.

Las metáforas conceptuales permiten comprender un concepto más abstracto o complejo por analogía con otro más simple o concreto. De esta forma, la utilización de cada expresión metafórica da cuenta de un sistema conceptual subyacente, algunas veces tan convencionalizado que los hablantes no son conscientes de que están realizando una analogía.

Cuando se establece una analogía entre dos conceptos, se desarrolla una red que vincula varios elementos del concepto más concreto con otros elementos del concepto metafórico. Esto quiere decir que las metáforas conceptuales son sistemáticas. Expresiones como "tu postura es indefendible" o "destruí tu argumento" o "si usas esa estrategia, voy a contratacar" son todas expresiones que refieren a la metáfora conceptual "una discusión es una guerra". A partir de una comparación general, "una discusión es una guerra", se estructura toda una serie de elementos análogos entre el concepto "discusión" y el concepto "guerra": se gana o se pierde terreno, se ataca una posición, se desarrollan estrategias, la interlocutora es vista como una oponente, las discusiones se ganan o pierden. 
Sin embargo, las metáforas conceptuales, además de sistemáticas, son parciales. La misma sistematicidad que permite comprender un aspecto de un concepto en términos de otro necesariamente va a ocultar algunas características de esos conceptos que serían incoherentes con la metáfora. Al enfocar aspectos de la discusión como una guerra, se pueden perder de vista los rasgos cooperativos de una discusión. Asimismo, no todos los elementos referidos a una guerra pueden ser utilizados para hablar metafóricamente de una discusión, es probable que haya algunos elementos del concepto más básico que también deban ser escondidos. Es decir, en una discusión no se lastima físicamente a la otra persona, no se utilizan armas, la que gana un debate no confisca los bienes de la otra persona, no se toman prisioneras, etc.

Por su parte, las categorías radiales son construcciones cognitivas necesarias para almacenar representaciones o imágenes del mundo en forma de prototipos. Por ejemplo, las personas no almacenan cada ejemplar animal o cada árbol que ven, sino prototipos. La idea de tigresa que alguien almacena en su cabeza puede ser la de una felina grande amarilla con rayas, aunque hay tigresas blancas. La imagen típica cuando se piensa en un árbol tiene hojas verdes y copa redondeada aunque hay árboles de diversas formas y colores.

Un concepto clave para comprender esta concepción de la categorización humana es el de parecidos de familia de Ludwig Wittgenstein ([1953] 1988): las categorías radiales no son definibles en términos de una lista de propiedades que comparte cada integrante de la categoría, sino que son caracterizadas por variaciones en un modelo central. Las integrantes centrales de las categorías radiales son un subtipo de lo que se conoce como prototipo, un elemento de una categoría que representa la categoría como un todo (en los ejemplos anteriores, la tigresa amarilla con rayas o el árbol de hojas verdes y copa redondeada).

Un tipo de prototipo es el estereotipo social, un modelo, con amplio alcance en una cultura, que permite realizar un juicio instantáneo, sin reflexión, sobre una categoría entera, asumiendo que el estereotipo es el caso típico. ${ }^{5}$ En Argentina existen muchos estereotipos vinculados con las personas de diferentes nacionalidades, por ejemplo, asociado a profesiones (Flax 2019, 2020) (uruguaya como portera, boliviana como verdulera, paraguaya como trabajadora de la construcción, entre otros).

\subsection{Los estudios sobre migración}

Desde el Análisis Crítico del Discurso varias autoras han estudiado las representaciones dominantes sobre migrantes en el discurso político y mediático. 
Según Wodak (2003) y Hart (2010), podemos encontrar una serie de topoi, propios de los discursos xenófobos, que son utilizados para persuadir de la amenaza que constituyen las migrantes y, de esa manera, activar respuestas emocionales como el miedo o el enojo:

\begin{tabular}{|l|l|}
\hline Topos & Asociación/premisa \\
\hline Carga & El out-group necesita ser mantenido por el in-group \\
\hline Caracter & El out-group tiene ciertas características indeseables \\
\hline Crimen & El out-group está compuesto por criminales \\
\hline Cultura & $\begin{array}{l}\text { El out-group tiene diferentes normas y valores que el in-group y son incapaces de } \\
\text { asimilación }\end{array}$ \\
\hline Peligro & El out-group es peligroso \\
\hline Desventaja & El out-group no trae ninguna ventaja o no es de ninguna utilidad para el in-group \\
\hline Enfermedad & El out-group es sucio y transmite enfermedades contagiosas \\
\hline Desplazamiento & $\begin{array}{l}\text { El out-group va a eventualmente sobrepasar en número o va a d ominar al in-group y } \\
\text { va a tener acceso privilegiado a los recursos socio -económicos limitados por sobre el } \\
\text { in-group }\end{array}$ \\
\hline Explotación & El out-group explota el sistema de servicios sociales del in-group \\
\hline Finanzas & El out-group presenta una costo económico para el in-group \\
\hline
\end{tabular}

Cuadro 2. Topoi recurrentes y sus asociaciones típicas (tomado de Hart 2010)

Por su parte, Hart (2010) rastrea cómo los medios de comunicación utilizan metáforas vinculadas con la guerra y con el agua para referirse a las migrantes. Según El Refaie (2001), la consecuencia lógica de tratar a las migrantes como un ejército invasor es defenderse y contratacar. Así el uso de metáforas de "guerra" en el discurso sobre migrantes hace que sea concebible tratar a las personas humanas indefensas como enemigas peligrosas y parece justificar una reacción de guerra. Por su parte, hay una serie de inferencias ideológicas disponibles al conceptualizar a las migrantes como agua: la metáfora implica que las migrantes son una sustancia inanimada $y$, por lo tanto, no tienen motivos, intenciones o voluntad. En otras palabras, la metáfora deshumaniza a las migrantes. Además, las conceptualiza como una masa única, enmascara su individualidad e implica que la migración es un fenómeno simple por el cual todos los casos pueden tratarse de la misma manera.

En Argentina, los estudios sobre migrantes propiamente desde el Análisis del Discurso son escasos. No obstante, desde disciplinas aledañas como la sociología, la antropología y las ciencias de la comunicación (Grimson 1999, 2006; Castiglione 2011; Novick 2008; Courtis y Longo 2000; Melella 2015a, 2015b) se estudió el discurso dominante, en particular, a partir de los años 90 . Estos estudios indican que tanto los medios de comunicación como las políticas asocian a las migrantes con la delincuencia y las colocan en el lugar de responsables por la desocupación que sufren las argentinas. 
En un trabajo anterior, (Flax 2019) mostramos cómo, durante el año 2010, el entonces Jefe de Gobierno de la Ciudad de Buenos Aires representaba a las migrantes como una invasión y una epidemia, y las vinculaba con el crimen.

\section{El corpus de análisis}

El libro editado por la Dirección Nacional de Migraciones se denomina Nosotros, los que vinieron. Ya esté título refleja una tensión entre "nosotras, las argentinas" y "ellas, las migrantes" al quebrar la concordancia sujeto-verbo. ¿Por qué no "nosotros, los que vinimos"? Definitivamente no es la hablante la que vino a la Argentina. Pero, al mismo tiempo, cabe preguntarse por la otra posibilidad que resolvería la tensión producto de la no concordancia de la persona gramatical: ¿Por qué no "ellos, los que vinieron"? El intento de fusión del "nosotras" con las migrantes no hace más que dejar en evidencia la operación discursiva: la división nosotras/ellas que se quiere esconder.

El subtítulo, a su vez, expresa "Testimonios de vida de inmigrantes. Vinieron a 'hacerse la América' y terminaron haciendo la Argentina” reproduciendo un lugar común en Argentina: ${ }^{6}$ la masiva inmigración europea de finales de siglo XIX y principios de siglo XX, que poco tiene que ver con los países de origen de las personas -mayoritariamente latinoamericanas- que llegaron al país en las últimas décadas. De esta manera, activa el estereotipo que asocia a la migrante que llega a la Argentina con una europea, pero no tiene sentido si la migrante proviene, de hecho, de otros países de América.

Por último, el libro tiene por lema "migrar es un derecho humano". Esta frase reenvía directamente a la Ley de Migraciones 25.871 sancionada en el año 2003 que, precisamente, define de esa manera a las migraciones, en oposición a la legislación anterior que la consideraba desde el punto de vista utilitario, la necesidad de mano de obra, y desde una óptica casi exclusivamente policial (Oteiza, Novick y Aruj 1997).

Como dijimos en la introducción, el libro está compuesto por treinta y siete historias.? Según los países de origen de sus protagonistas, se encuentran distribuidas de la siguiente manera: 


\begin{tabular}{|l|l|l|l|}
\hline \multicolumn{1}{|c|}{ América } & \multicolumn{1}{c|}{ Esia } & \multicolumn{1}{c|}{ África } \\
\hline Uruguay & Italia (3) & China & Ghana \\
\hline Brasil & Alemania & Georgia & Nigeria \\
\hline Estados Unidos (2) & Albania & Kazajistán & \\
\hline Cuba & España (2) & Siria & \\
\hline Paraguay (2) & Francia (3) & China & \\
\hline Perú (2) & Catalunya & Mongolia & \\
\hline Chile & Polonia & & \\
\hline República Dominicana & Ucrania & & \\
\hline Venezuela (2) & & & \\
\hline Bolivia & & & \\
\hline Ecuador & & & \\
\hline México & & & \\
\hline Colombia & & & \\
\hline
\end{tabular}

Cuadro 3. Distribución de entrevistas según países

Resulta necesario destacar que todas las historias de vida que presenta el libro muestran migraciones exitosas. Es decir, personas que poseen empleos en un país con altas tasas de desocupación, que lograron desarrollarse en lo personal, mejorar su calidad de vida material y, en muchos casos, incluso tener trabajos calificados o profesionales. Por otra parte, prácticamente no se relatan situaciones de discriminaciones o se las mitiga.

Para su análisis según los dos ejes propuestos, escogimos once de las treinta y siete narraciones. La selección se realizó tomando como criterio la distribución de continentes y países de origen representados. Las narraciones también presentan diferencias con respecto al género, la edad, la profesión u oficio de sus protagonistas. Las historias seleccionadas fueron las siguientes: 1) Karl Moses, Alemania; 2) Egidio Trevisan, Italia; 3) Jeff Aaliya, Ghana; 4) Jose y Rosa Wang, China; 5) Soledad Crispín, Perú; 6) Mijail Bubnov, Kazajstán; 7) Obadiah Oghoerore Alegbe, Nigeria; 8) Pablo Wozniuk, Ucrania; 9) Rafael Hugo Reyes Gainza y Félix Ramiro Gutiérrez Uriarte, Bolivia; 10) Verónica Mora, Venezuela; 11) Ignasi Almirall, Cataluña.

\section{Las historias de vida}

\subsection{Acciones sociales atribuidas a las migrantes}

Para nuestro análisis, tomamos únicamente las formas verbales -ya sea conjugadas o no- y no ahondamos en formas más abstractas de representación de la acción social, como las nominalizaciones, que justamente pueden servir para mitigar la relación entre las actoras sociales y las 
acciones en las que participan. El objetivo es determinar con que acciones se busca asociar a las migrantes.

A partir del siguiente cuadro, podemos observar que prevalecen, de manera muy marcada, las acciones materiales por sobre el resto. Además, el tipo de acciones materiales son, en su mayoría, acciones no transactivas vinculadas con verbos de movimiento, que marcan el viaje o recorrido de las migrantes hasta asentarse en el país ("llegó", "se alojaron”, "escapé”, “atravesé”, "volví", "partí") o acciones vinculadas con lo laboral ("trabajé”, "no paré”, "participé”, “entrena”). En esta última categoría, no obstante, se pueden encontrar también cláusulas transactivas como "regenteamos un hotel", "desarrolla softwares").

\begin{tabular}{|l|l|l|l|l|}
\hline Narrativa & Material & Cognitiva & Verbal & Reacción \\
\hline Karl Moses & 34 & 22 & 12 & 7 \\
\hline Egidio Trevisan & 57 & 6 & 4 & 1 \\
\hline Ignasi Almirall & 51 & 7 & 7 & 3 \\
\hline Jeff Aaliya & 52 & 17 & 15 & 9 \\
\hline José y Rosa Wang & 41 & 15 & 15 & 7 \\
\hline Mijail Bubnov & 55 & 14 & 13 & 5 \\
\hline $\begin{array}{l}\text { Obadiah Oghoerore } \\
\text { Alegbe }\end{array}$ & 47 & 23 & 19 & 3 \\
\hline Pablo Wozniuk & 41 & 9 & 12 & 4 \\
\hline $\begin{array}{l}\text { Rafael Hugo Reyes } \\
\text { Gainza }\end{array}$ & 48 & 7 & 17 & 1 \\
\hline Soledad Crispín & 58 & 9 & 10 & 5 \\
\hline Verónica Mora & 38 & 7 & 6 & 0 \\
\hline
\end{tabular}

Tabla 1. Distribución de procesos en las entrevistas

Consideramos relevante estos datos porque dicen mucho sobre cómo se decide representar a las migrantes o qué aspectos de su existencia se decide incluir. No es lo mismo que el foco esté puesto en sus actos, en sus ideas y opiniones, o en los sentimientos, sensaciones y reacciones que el cambio de país les produjo.

En nuestro corpus, los logros laborales son todos materiales, no se hace hincapié en la producción intelectual ni siquiera en los casos en que el tipo de trabajo lo habilita especialmente, como el periodismo (Karl Moses), la docencia (Obadiah Oghoerore Alegbe) o la psiquiatría (Verónica Mora). En la mayoría de las narraciones, se cuenta todo el periplo por el que tuvieron que pasar las entrevistadas y sus familiares hasta radicarse en el país con escasas referencias a qué tipo de impacto psicológico tuvo en sus vidas.

En este sentido, consideramos que, si bien las historias de vida permiten la humanización de las migrantes al otorgarle importancia a la biografía de cada una, el foco se encuentra puesto en el viaje y en los logros materiales en el país receptor antes que en las opiniones que tie- 
nen las entrevistadas sobre Argentina, sus habitantes o su propia experiencia en la cultura nueva. En todas las narraciones analizadas, se incluye algún fragmento referido a la integración de las migrantes en el país, pero no posee la misma relevancia que se le otorga a sus acciones materiales, particularmente en el ámbito laboral. Esto coincidiría con una visión utilitarista de la migración, donde las extranjeras deben ser valoradas por lo que aportan al país (Domenech 2009).

\subsection{Los marcos conceptuales}

En las once narraciones seleccionadas, rastreamos las categorías y metáforas utilizadas para observar qué marcos conceptuales utiliza la Dirección Nacional de Migraciones para describir a las migrantes. Estas se definen básicamente por su trabajo y su familia. Estos dos marcos conceptuales aparecen en todas las historias de vida del corpus. En algunos casos el trabajo se asocia con una vocación de toda la vida (el teatro, por ejemplo), o con algún tipo de profesión (periodista, médico). En otros casos, se trata de trabajos de oficio.

Activar representaciones familiares y laborales ya es una forma de generar una determinada identidad para las migrantes, asociada a los valores de la familia y a la cultura del trabajo, que las coloca en el lugar del prototipo de la ciudadana modelo (Lakoff 2010). Las presenta como miembros productivos de una comunidad, atadas a compromisos y arraigadas a su lugar de residencia -en muchos casos se habla de hijas que nacieron en la Argentina- y de manera implícita refuta las asociaciones que forman parte del sentido común que vinculan a la migrante con la inseguridad y el crimen (Melella 2015a; Courtis y Longo Elia 2000).

Así como en todas las narraciones se activa el marco conceptual del trabajo, en 8 de las 11 narraciones, se lo asocia con el marco conceptual del sacrificio. En algunos casos, el sacrificio se vincula con tareas especialmente arduas o trabajos que en condiciones más favorables no se elegirían. Observamos, a partir del cuadro 4, que en varios casos se trata de trabajos extremadamente exigentes desde un punto de vista físico y se explicita la imposibilidad de seleccionarlos: las migrantes deben tomar cualquier trabajo, sin importar en qué consista, cuánto se pagué, porque no hay otra posibilidad para subsistir. Si bien la insistencia en el marco conceptual del trabajo busca generar empatía hacia las migrantes, también pone de manifiesto la profunda desigualdad laboral que sufren las extranjeras que deciden o se ven obligadas a vivir en la Argentina. 


\begin{tabular}{|l|l|}
\hline $\begin{array}{l}\text { Carl le propuso a la agencia alemana terminar el contrato fijo y quedarse } \\
\text { en la Argentina como free-lance, aceptando condiciones económicas } \\
\text { inferiores, pero con más tiempo libre para hacer otros trabajos (Carl Moses). }\end{array}$ & $\begin{array}{l}\text { Peores condiciones } \\
\text { económicas. }\end{array}$ \\
\hline $\begin{array}{l}\text { Gigio cortaba piedras para la construcción, oficio al que se dedicó toda su } \\
\text { vida. "No tenía experiencia en trabajar la piedra, era muy duro" (Egidio } \\
\text { Trevisan). }\end{array}$ & Trabajo pesado. \\
\hline $\begin{array}{l}\text { "A la recepcionista del hotel le dejaban anuncios de trabajo y vi que había } \\
\text { uno que nadie quería tomar porque era una familia con cinco chicos. Como } \\
\text { no tenía dinero no podía darme el lujo de esperar un trabajo que me } \\
\text { convenga y lo acepté." (Soledad Crispín) }\end{array}$ & $\begin{array}{l}\text { Trabajo pesado, } \\
\text { imposibilidad de } \\
\text { seleccionar trabajo. }\end{array}$ \\
\hline $\begin{array}{l}\text { Cuando llegó, tuvo que luchar para vivir, aprovechando todas las } \\
\text { oportunidades de trabajo que se le presentaban (Jeff Aaliya). }\end{array}$ & $\begin{array}{l}\text { Imposibilidad de } \\
\text { seleccionar trabajo. }\end{array}$ \\
\hline $\begin{array}{l}\text { Estos son tiempos de retiro para Pablo y Sofía, las arduas labores del campo } \\
\text { quedaron atrás. "Eso quedó para mis hijos, que siguen trabajando la tierra. }\end{array}$ & $\begin{array}{l}\text { Trabajo pesado, trabajo } \\
\text { en la ancianidad. }\end{array}$ \\
$\begin{array}{l}\text { Nosotros pusimos un almacén en las afueras de la capital formoseña, y ya } \\
\text { hace diez años que estamos acá" (Pablo Wozniuk). }\end{array}$ & \\
\hline $\begin{array}{l}\text { La tenacidad laboral de los chinos es un clásico, que une sus historias con las } \\
\text { de sus compatriotas. En José cobra forma en su paso al frente en distintos } \\
\text { supermercados y restaurantes (José y Rosa Wang). }\end{array}$ & $\begin{array}{l}\text { Imposibilidad de } \\
\text { seleccionar trabajo. }\end{array}$ \\
\hline
\end{tabular}

Cuadro 4. Sacrificio laboral

En otros casos, se tematiza también el descenso social que supone trasladarse a un nuevo país: los títulos terciarios y universitarios no son reconocidos en el país receptor y las migrantes debe hacer un gran esfuerzo para volver a estudiar al mismo tiempo que trabajan:

\begin{tabular}{|c|c|}
\hline $\begin{array}{l}\text { A pesar de su formación, Mikhail comenzó trabajando como pintor, en } \\
\text { tareas de mantenimiento y en una fábrica textil. Su esposa Irina fue } \\
\text { mucama del hotel donde se hospedaban, luego moza de un café, estudió } \\
\text { peluquería y trabajó en ese rubro. "Pero después mi esposo que ría que yo } \\
\text { estuviera en casa y así fue, entonces me puse un taller de costura, algo que } \\
\text { sabía desde chiquita y me gustó", comentó. Él, en tanto, se ocupó de } \\
\text { revalidar su título. "En esa época, trabajaba mediodía y el resto del tiempo } \\
\text { estudiaba; dormía tres horas" (Mijail Bubnov) }\end{array}$ & $\begin{array}{l}\text { Degradación laboral, } \\
\text { volver a realizar los } \\
\text { mismos estudios } \\
\text { universitarios. }\end{array}$ \\
\hline $\begin{array}{l}\text { "Vine como técnico de telecomunicaciones pero hice escuela de adultos } \\
\text { acelerado tres años para poder ingresar al ITBA (Instituto Tecnológico } \\
\text { Buenos Aires). La equivalencia me iba a demorar más que empezar la } \\
\text { carrera de cero", asegura (Obadiah Oghoerore Alegbe) }\end{array}$ & $\begin{array}{l}\text { Volver a realizar los } \\
\text { mismos estudios } \\
\text { secundarios y terciarios. }\end{array}$ \\
\hline
\end{tabular}

Cuadro 5. Sacrificio laboral: descenso social, estudios

El sacrificio también se vincula con las condiciones de llegada. En 3 de las 11 narraciones el sacrificio de la llegada se asocia a viviendas pobres, hacinadas, sucias, etc. Las migrantes no naturalizan estas condiciones, no justifican el tener que pasar por ciertas penurias para ser recibidas y aceptadas en un nuevo país (Soledad Crisín y Mijail Bubnov): 


\begin{tabular}{|c|c|}
\hline $\begin{array}{l}\text { En un principio, se instalaron en una habitación de la casa de un familiar } \\
\text { y luego se fueron a } 30 \text { kilómetros de la ciudad, hacia la montaña, en La } \\
\text { Ollada. Vivían los tres en apenas una pieza en medio de una gran } \\
\text { soledad porque en aquel momento alli no existía nada (Egidio Trevisan). }\end{array}$ & $\begin{array}{l}\text { Hacinamiento, entorno } \\
\text { inhóspito. }\end{array}$ \\
\hline $\begin{array}{l}\text { En el Hotel de Inmigrantes estuvieron dos noches. "Recuerdo que había } \\
\text { muchas pulgas, pero nos trataron muy bien y volvimos a estar los tres } \\
\text { juntos, porque en el barco no fue posible" (Egidio Trevisan). }\end{array}$ & Condiciones insalubres. \\
\hline $\begin{array}{l}\text { Como la vida en la montaña era muy difícil, la familia decidió viajar a la } \\
\text { ciudad, donde en un principio alquilaron una piecita. Pero muy } \\
\text { lentamente y con un gran esfuerzo, lograron construir su hogar (Egidio } \\
\text { Trevisan). }\end{array}$ & $\begin{array}{l}\text { Hacinamiento, entorno } \\
\text { inhóspito. }\end{array}$ \\
\hline $\begin{array}{l}\text { Era una pieza horrorosa y encima, compartida. Una señora grande que } \\
\text { ahí se alojaba me tiró buena onda y me levantó el ánimo (Soledad } \\
\text { Crispín). }\end{array}$ & Condiciones desagradables. \\
\hline $\begin{array}{l}\text { "Nos dejó en un hotel sobre las calle Chile y Chacabuco y cuando } \\
\text { entramos nos quisimos morir. Era una pequeña habitación con cuatro } \\
\text { camas y sin ventanas, por la que pagamos i300 dólares al mes!" (Mijail } \\
\text { Bubnov). }\end{array}$ & $\begin{array}{l}\text { Hacinamiento, condiciones } \\
\text { desagradables. }\end{array}$ \\
\hline
\end{tabular}

Cuadro 6. Condiciones materiales de llegada

\begin{tabular}{|l|l|}
\hline $\begin{array}{l}\text { Si bien el cambio fue positivo, insertarse en un nuevo lugar con } \\
\text { costumbres, lengua y actividades diferentes no fue nada fácil. "Cuando } \\
\text { llegamos a Buenos Aires, no sabíamos el idioma ni teníamos amigos" } \\
\text { (Mijail Bubnov). }\end{array}$ & $\begin{array}{l}\text { Desconocimiento total del } \\
\text { idioma, desamparo. }\end{array}$ \\
\hline $\begin{array}{l}\text { "Ella se había quedado, así que la extrañaba mucho y encima estaba } \\
\text { embarazada. Fue difícil, además, los primeros meses sentía que no podía } \\
\text { con el idioma. No sabía qué hacer. Más de una vez pensé en tomarme el } \\
\text { avión de vuelta. Pero como me costó tanto venir, me decía: 'si otros } \\
\text { pueden quedarse, yo también. Voy a aguantar'. Y Yaguanté" (José y Rosa } \\
\text { Wang). }\end{array}$ & $\begin{array}{l}\text { Desconocimiento total del } \\
\text { idioma, desarraigo, }\end{array}$ \\
\hline $\begin{array}{l}\text { "Mi abuelo había venido al país diez años antes. Lo mandaron a } \\
\text { Mendoza pero no se adaptó, así que decidió probar suerte en Igorreta, } \\
\text { Formosa" (Pablo Wozniuk). }\end{array}$ & Inadaptación. \\
\hline $\begin{array}{l}\text { "Estaba muerta de susto porque pensaba que no iba a poder responder } \\
\text { sobre historia o geografía argentina, pero los otros niños estaban peor } \\
\text { porque ellos... jno conocían el español!" (Verónica Mora). }\end{array}$ & $\begin{array}{l}\text { Miedo, desconocimiento del } \\
\text { idioma. }\end{array}$ \\
\hline $\begin{array}{l}\text { Sin embargo, el afecto, la adaptación e integración -costosa al principio y } \\
\text { plena después- hicieron que regresaran a nuestra patria (Verónica }\end{array}$ & Inadaptación. \\
Mora). & \\
\hline "A los tres meses empecé a manejarme más o menos con el idioma \\
hablando como Tarzán pero me hacía entender" (Obadiah Oghoerore \\
Alegbe).
\end{tabular}

Cuadro 7. Condiciones no materiales de llegada 
Todos los marcos conceptuales hasta aquí mencionados se utilizan para delinear la identidad de las migrantes como personas esforzadas, que merecen reconocimiento, que vienen a trabajar y no a delinquir; no obstante, ponen al descubierto las condiciones laborales y habitacionales negativas que les ofrece la Argentina a las extranjeras.

En cinco narraciones, el padecimiento de la llegada tiene que ver con condiciones no materiales: la incomprensión del idioma, la sensación de desarraigo y el miedo. Aquí el marco del sacrificio se activa, además, en tanto la heroína del relato siempre resiste y se sobrepone a las dificultades.

Sin embargo, las dificultades de la llegada se matizan porque varias narraciones (5 de 11), incluidas algunas que hablan de la dificultad del idioma o del desarraigo, enfatizan la facilidad de la integración a partir de la propia voz de las migrantes (discurso referido directo). Esto se vincula con dos cuestiones: la construcción de la identidad de la argentina (amistosa, afable, "dispuesta a ayudar", "amable") y la comparación de Argentina con otros países.

En referencia a la primera cuestión, cabe destacar que la explicitación por parte de las migrantes de una disposición generalmente positiva de las argentinas hacia ellas choca con las profundas injusticias que subyacen a las descripciones de las condiciones de llegada, los trabajos que obtienen y la imposibilidad -en la mayoría de los casos en que poseen una- de poder vivir de su profesión.

Con respecto a lo segundo, por un lado, la comparación de Buenos Aires con ciudades de Europa (lugar común de la identidad argentina) otorga familiaridad al país de llegada (fragmento 1); por otro lado, se realiza una diferenciación con países que son una peor opción ${ }^{9}$ para las migrantes por las discriminaciones que sufren (fragmento 4):

(1) A la pareja, la ciudad nunca le pareció extraña. Enseguida la compararon con algunas ciudades de España e incluso de Francia. Por su trabajo, tuvo una inserción automática en la comunidad alemana. Su antecesor lo introdujo en el círculo de colaboradores, colegas y contactos que eran, en su mayoría, compatriotas suyos. Sin embargo, en la vida personal fraternizaron rápidamente con argentinos. "Más allá de los defectos de infraestructura u organizativos que en ese momento eran miles, se nos hizo todo muy fácil” (Carl Moses).

(2) "Acá aunque no hables el idioma hay gente que te va a entender. En la Argentina hay buena gente dispuesta a ayudar” (Jeff Aaliya).

(3) "Enseguida conseguimos una vivienda cómoda en Capital. A los 8 días tenía la cédula y avisos ofreciendo trabajo. Fui seleccionado entre muchos postulantes argentinos y entré en Sudamtex" (Ignasi Almirall).

(4) "Aquí la gente es muy amable. Por ejemplo, cuando no conocía las calles y preguntaba como podía, en general me tenían paciencia y me trataban bien. Sí, algunas personas no son tan amables y te miran mal; pero sé que sí hay discriminación contra los chinos en Japón y en Estados Unidos. Tengo unos amigos que estuvieron en esos países y se vinieron a la Argentina por esa razón” (José y Rosa Wang).

Lengua y migración / Language and Migration 12:2 (2020), 45-64

Edición impresa: ISSN 1889-5425. Edición en línea: ISSN 2660-7166. @ Universidad de Alcalá 
(5) Cuenta que cuando llegó los argentinos lo integraron bien: "Me enseñaron a hablar, me enseñaron sus bromas. Me hicieron comprender que la palabra negro no era un insulto". También recuerda cuando salían por los boliches de San Telmo, Recoleta, Pasaje Bollini o San Isidro (Obadiah Oghoerore Alegbe).

Otro marco conceptual que se activa en la mayoría (6 de 11) de las narraciones analizadas es el de la peripecia del viaje. De hecho, es explícitamente calificado como "aventura” en una ocasión (Pablo Wozniuk). En muchos casos, la llegada tiene obstáculos y hay todo un detenimiento en el relato de esos obstáculos. Esto, una vez más, permite asociar a las migrantes con el campo conceptual del sufrimiento y de una vida sacrificada.

\begin{tabular}{|c|c|}
\hline $\begin{array}{l}\text { Fue así que se embarcaron en Génova, en el barco de carga Ugolino Vivaldi, } \\
\text { que "venía lleno de emigrantes italianos. Eso sí, los hombres por un lado y } \\
\text { las mujeres por otro. Recuerdo que la comida era muy mala y esto hizo que } \\
\text { mi esposa contrajera 'el mal del mar' y estuvo con vómitos durante el viaje } \\
\text { que duró } 22 \text { días. Pasamos por Barcelona, las Islas Canarias, Río de Janeiro, } \\
\text { Santos y Montevideo hasta arribar al puerto de Buenos Aires" (Egidio Trevisan) }\end{array}$ & $\begin{array}{l}\text { Migración europea, } \\
\text { primera mitad siglo XX, } \\
\text { viaje en barco. Relato de } \\
\text { escalas y dificultades del } \\
\text { viaje. }\end{array}$ \\
\hline $\begin{array}{l}\text { A los } 22 \text { decidió hacer un viaje por Centroamérica. Empezó por Cuba, luego } \\
\text { Ecuador y después Argentina, donde se quedó. Era el año } 98 \text { (Jeff Aaliya). }\end{array}$ & $\begin{array}{l}\text { Migración africana, finales } \\
\text { siglo XX. Relato de escalas. }\end{array}$ \\
\hline $\begin{array}{l}\text { Presentaron sus papeles a Canadá, España y la Argentina. Sin embargo, } \\
\text { debido a las dificultades que se le presentaron en la tramitación de los dos } \\
\text { primeros, eligieron nuestro suelo. "El país que parecía más fácil, que } \\
\text { aceptaron nuestra documentación y nos permitieron entrar fue la Argentina, } \\
\text { por esta razón vinimos para acá. Antes, vendimos todo lo que teníamos } \\
\text { pero como el mercado estaba tan destruido, sólo nos alcanzó para pagar los } \\
\text { pasajes y el trámite de Migraciones. Llegamos con } 3.000 \text { dólares" (Mijail Bubnov). }\end{array}$ & $\begin{array}{l}\text { asiática, } \\
\text { XX. Relato } \\
\text { arativos del } \\
\text { ites y } \\
\text { económicas. }\end{array}$ \\
\hline $\begin{array}{l}\text { La aventura del viaje hacia la nueva patria es un recuerdo impostergable } \\
\text { para este inmigrante: "Ilegamos en barco primero a Buenos Aires, y desde } \\
\text { ahí a Formosa. Tardamos 18, } 20 \text { días, con escala en Marsella, Francia. El } \\
\text { vapor se llamaba Campana, luego me enteré que lo hundieron los } \\
\text { alemanes en la guerra. Cada familia tenía camarote. El último tramo por } \\
\text { tierra hasta Formosa tuvo sus complicaciones: ni había caminos de tierra, } \\
\text { había que inventarlos" (Pablo Wozniuk). }\end{array}$ & $\begin{array}{l}\text { Migración europea } \\
\text { (este), primera mitad } \\
\text { del siglo XX, viaje en } \\
\text { barco y viaje por tierra. } \\
\text { Relato de las escalas y } \\
\text { dificultades del viaje. }\end{array}$ \\
\hline $\begin{array}{l}\text { 977. "En el avión estuve orando, rezando y } \\
\text { e pisaba para poder quedarme acá y crear un } \\
\text { badiah Oghoerore Alegbe). }\end{array}$ & $\begin{array}{l}\text { fricana, } \\
\text { glo XX, viaje en } \\
\text { o de estado } \\
\text { ante el viaje. }\end{array}$ \\
\hline $\begin{array}{l}\text { Partió de Chimbote rumbo a Lima "con una valija con ropa y muchas ganas } \\
\text { de trabajar. En el viaje venía con ilusión de que me fuera bien pero con la } \\
\text { pena de dejar la familia". Allí conoció a Lucy, una mujer que buscaba el } \\
\text { mismo destino, y viajaron juntas el largo trayecto hasta llegar a Retiro. "Al } \\
\text { principio pensé que quería robarme, yo venía del interior y tenía } \\
\text { desconfianza de la gran ciudad. Pensaba que me seguía pero era que tenía } \\
\text { que hacer los mismos trámites que yo", relató risueña. A su compañera de } \\
\text { ruta e ilusiones la esperaba en Buenos Aires una amiga que las llevó a un }\end{array}$ & $\begin{array}{l}\text { Migración } \\
\text { latinoamericana, finales } \\
\text { de siglo XX, viaje por } \\
\text { tierra. Relato de } \\
\text { esperanzas, miedos y } \\
\text { dificultades. }\end{array}$ \\
\hline
\end{tabular}


Un tema que aparece en varias, aunque no en todas las narraciones, se refiere a las condiciones de vida en el país de origen de las migrantes y los motivos de la partida. Sin embargo, si bien en algunos casos se lo asocia con el marco conceptual de la guerra (y todas las situaciones catastróficas que acarrea, por ejemplo, pérdida del hogar, hambre, desocupación, censura) (4 de 11 narraciones), otras historias (3 de 11) relacionan la decisión de emigrar con el marco del progreso personal y Argentina se describe como un país con mayores oportunidades. En el caso de las guerras, se trata de migraciones forzadas:

\begin{tabular}{|l|l|}
\hline $\begin{array}{l}\text { "Tras la guerra fue muy difícil trabajar. Papá perdió su empleo y murió en } \\
\text { el 44. Nos quedamos, mamá, mi hermana y mi cuñado. Aguantamos muy } \\
\text { mal hasta el 50. Yo trabajaba en una casa de géne ros de punto, pero el } \\
\text { sueldo era mísero. Además, había racionamiento y comprábamos a precios } \\
\text { muy altos en el mercado negro" (Ignasi Admirall). }\end{array}$ & \\
\hline $\begin{array}{l}\text { "Nuestro pueblo fue bombardeado varias veces y la casa de Cornelia -que } \\
\text { vivía en la ciudad- fue destruida por las bombas de los aviones así que se } \\
\text { vino a vivir a nuestra casa, que estaba en el campo. Ahí la conoci" (Egidio } \\
\text { Trevisan). }\end{array}$ & \multirow{2}{*}{$\begin{array}{l}\text { Segunda Guerra } \\
\text { Luego de la contienda mundial, Trevisan, vin o a la Argentina motivado por } \\
\text { sus hermanos que ya estaban aquí y le relataron por carta las bondades del } \\
\text { país. "La situación era muy difíil en Italia. No había trabajo, alimento ni } \\
\text { esperanzas", comentó Gigio, quien lo vivió muy de cerca (Egidio Trevisan). }\end{array}$} \\
\hline $\begin{array}{l}\text { "En la Argentina vivo desde el año 32, hice sexto grado en este país. Aquí } \\
\text { llegué porque Bolivia estaba en la Guerra del Chaco, con Paraguay, y mis } \\
\text { padres tenían miedo de que se extendiera, así que me mandaron a vivir con } \\
\text { unos parientes" (Rafael Hugo Reyes Gainza). }\end{array}$ \\
\hline $\begin{array}{l}\text { Hombres y mujeres que en sus tierras de origen pergeñaban un futuro de } \\
\text { labranza, pero que la guerra y la miseria los obligó a trasladar su esfuerzo } \\
\text { hacia lejanas latitudes con sus hijos a cuestas (Pablo Wozniuk). }\end{array}$ & $\begin{array}{l}\text { Primera Guerra } \\
\text { Mundial, Guerra } \\
\text { República de Polonia- } \\
\text { Unión de Repúblicas }\end{array}$ \\
\hline
\end{tabular}

Cuadro 9. Marco conceptual guerra

Cuando se trata de mejorar la situación económica u obtener mejores oportunidades de vida, se trataría de casos de migraciones voluntarias. No obstante, la situación económica de un país puede matizar esa idea de autodeterminación (Soledad Crispín): 


\begin{tabular}{|l|l|}
\hline $\begin{array}{l}\text { "Vivíamos en Ying Tan, una pequeña ciudad de } 200.000 \text { habitantes. Ahí } \\
\text { era operario en una fábrica de detergentes... Pensaba que si me quedaba, } \\
\text { mi vida no iba a avanzar mucho, y eso fue lo que motivó a venirme. Mi }\end{array}$ & Progreso personal. \\
$\begin{array}{l}\text { padre me decía: 'Argentina es lindo país, tiene buen clima y si tienes } \\
\text { ganas de trabajar vas a trabajar y a progresar" (José Wang). }\end{array}$ & \\
\hline $\begin{array}{l}\text { Ciudadanos de las más remotas nacionalidades eligieron y siguen } \\
\text { prefiriendo la Argentina como destino para construir una vida mejor" } \\
\text { (Mijail Bubnov). }\end{array}$ & $\begin{array}{l}\text { Mejora de las } \\
\text { condiciones de vida } \\
\text { (generalización del } \\
\text { narrador). }\end{array}$ \\
\hline $\begin{array}{l}\text { "En Perú había escuchado que aquí las mujeres encontraban trabajo más } \\
\text { rápido y que la paga era buena. En mi país la mujer depende del hombre } \\
\text { porque es difícil conseguir trabajo o pagan mal" (Soledad Crispín). }\end{array}$ & $\begin{array}{l}\text { Mejora de las } \\
\text { condiciones de vida: } \\
\text { desocupación, pobreza. }\end{array}$ \\
\hline
\end{tabular}

Cuadro 10. Marco conceptual mejoras en las condiciones de vida

\section{Reflexiones finales}

En este trabajo, examinamos la construcción que la Dirección Nacional de Migraciones de Argentina realiza de las migrantes en su libro Nosotros, los que vinieron a partir de dos ejes de análisis: las acciones sociales y los marcos conceptuales con los que se relaciona a las migrantes.

Con respecto a las acciones sociales, los resultados arrojaron una mayoría de acciones materiales por sobre las acciones que representan las ideas, opiniones o sentimientos de quienes migraron a la Argentina. En otras palabras, prevalece la imagen de las migrantes haciendo, antes que hablando, pensando o sintiendo. Las acciones materiales refieren principalmente al periplo de su viaje y a las actividades laborales que realizan en el país. Si bien suponen una agencialidad, y eventualmente un grado de poder, mayor por parte de las actoras sociales que otro tipo de acciones sociales, también podemos interpretarlo como una focalización en lo que aportan materialmente a Argentina antes que en cómo se siente o en qué opinión tienen sobre el país receptor.

Este resultado se puede relacionar con el análisis de los marcos conceptuales. En todas las narraciones consideradas se activan los marcos conceptuales de la familia y el trabajo. Las migrantes son representadas, por lo tanto, como personas que se insertan en la sociedad, forman una familia y contribuyen de manera activa con el país. El marco conceptual del trabajo se activa en asociación con otro marco: el del sacrificio. Los esfuerzos y padecimientos van a atravesar otros aspectos de la vida de la migrante: su viaje hacia la Argentina, las condiciones de vida a su llegada y, en algunos casos, también las condiciones de vida en su país de origen antes de emigrar. Sin embargo, la migrante es la persona que se repone a estas adversidades, no solo por desplazarse hacia un país que ofrecería una mejor vida que su país de origen, sino también porque logra revertir las penosas condiciones de su llegada. 
En resumen, la identidad que se construye para la migrante es la de una persona que tuvo una vida difícil, llena de padecimientos, que busca una vida mejor y, para ello, atraviesa un viaje que puede presentar más obstáculos y dificultades, que se sobrepone a todos ellos a través del trabajo duro y logra formar una familia y tener una vida tranquila e integrada en el país que la recibe. No obstante, el costo de construir esta imagen de la migrante es silenciar por qué deben pasar por algunos de estos obstáculos, en particular los referidos al país receptor, como los trabajos físicamente muy exigentes o que no reconocen la preparación previa de las migrantes, el descenso en el nivel económico o las malas condiciones de vida durante el primer tiempo en el país.

Si el objetivo de la publicación de este libro es generar empatía y aceptación hacia las personas migrantes y disipar los prejuicios del discurso dominante que asocian a las migrantes con la inseguridad y el crimen (Melella 2015a; Courtis y Longo Elia 2000), consideramos que el libro podría ser exitoso. Construye una imagen humanizada de las migrantes, a diferencia de los discursos xenófobos (Hart 2010; Flax 2019) que las deshumanizan o tratan como masas o números, por ejemplo, al utilizar metáforas que las asocian con parásitos, plagas, olas o inundaciones. La historia de vida como género discursivo, en cambio, permite devolverles no solo su humanidad, sino también su individualidad. Por otro lado, logra ubicarlas en situaciones que podrían generar empatía en el in-group (guerra, pobreza) y acercan a la migrante a la lectora (las hijas, la vida familiar, el trabajo) y las construyen como el prototipo de la ciudadana modelo.

Sin embargo, consideramos que al construir historias que pasan por los mismos temas y activan los mismos marcos conceptuales, en el afán de construir un contra-discurso, se corre el riesgo de continuar generando una imagen estereotipada de las migrantes. Por otro parte, el libro construye una imagen idealizada tanto de las argentinas y de las migrantes como de su relación, que minimiza -casi en el límite del silencio- los enfrentamientos, la tensión, la discriminación o la violencia. Por último, no solo es silenciada la discriminación cotidiana que sufren las migrantes en Argentina, sino también la realidad de miles de migrantes que no se ajustan al modelo exitista presentado por el libro y que no poseen condiciones laborales y de vivienda dignas.

A pesar de ello y aunque la circulación de este tipo de publicaciones es limitada, la insistencia en este tipo de narraciones podría lograr cambiar los marcos con los que se asocia a las migrantes (peligro, inseguridad, falta de trabajo, utilización de recursos públicos, etc.) por otros vinculados a la contribución que las migrantes realizan en el país receptor, su voluntad de trabajo y de adaptación. Consideramos que podría resultar beneficioso la inclusión de narrativas de este tipo, a pesar de sus falencias, en determina- 
dos materiales como, por ejemplo, los manuales escolares que suelen representar a las migrantes como números o estadísticas.

Rocío Flax

Consejo Nacional de Investigaciones Científicas y Técnicas (CONICET)

Instituto de Lingüística, Facultad de Filosofía y Letras, Universidad de Buenos Aires 25 de mayo $2211^{\circ}$ piso. (C1002ABE) Ciudad Autónoma de Buenos Aires, Argentina Correo: rocioflax@educ.ar

ORCID: 0000-0003-4892-0925

Recepción: 29/09/2019; Aceptación: 20/05/2020

\section{Notas}

1 El presente trabajo se encuentra escrito femenino genérico tal como se utiliza en trabajos anteriores de Análisis del Discurso (Fairclough 1992, 2014), en tanto no existe aún en español una forma neutra consensuada como sucede con el idioma inglés (Cardelli 2018; Sarlo y Kalinowski 2019).

2 La DNM depende del Ministerio del Interior, Obras públicas y Vivienda de la Nación.

3 En el año 2015, se publica un segundo volumen que lleva el mismo título.

4 En una sola historia del libro, en un fragmento, aparecen de manera explícita algunas de las preguntas realizadas por la entrevistadora y la respuesta de la entrevistada.

5 Los estereotipos se generan a través de un modelo cognitivo metonímico. Se toma la parte (alguna persona famosa o algunos casos muy conocidos) como si se tratara de toda la categoría (Lakoff 1987; Hart 2010).

6 "Hacer la América" es una metáfora que si bien puede tener el significado de construcción de un continente (sobre todo considerando el imaginario del desierto, necesitado de la civilización europea para que el país pueda desarrollarse, que fuera hegemónico durante el siglo XIX en Argentina), tiene otro uso que se ve reforzado por el reflexivo "se" ("hacerse la América"). Esta expresión se utiliza desde principios del siglo XX para referirse a las europeas que venían a América a hacer fortuna (Moliner 2007) y luego tenían planificado regresar a su país (Discepolo [1925] 2006). Este sentido, tiene un matiz negativo, de aprovechamiento, desagradecimiento, etc.

7 Una de las entrevistas se encuentra representada en dos ocasiones en el cuadro ya que refiere a una pareja cubano-española.

8 Aquí se puede observar la presencia de un estereotipo con respecto a las personas que provienen de China.

9 Nótese que la valoración de Argentina no se realiza de manera directa y positiva. No se dice que aquí no se discrimina, sino que en otros países se discrimina más.

\section{Referencias bibliográficas}

Cardelli, Marina. 2018. "La reacción conservadora. Algunas preguntas teóricas en torno al debate sobre el plural del español y la aparición de la 'e' como práctica de lenguaje inclusivo en Argentina". Entornos, 31:1. 99-113.

Castiglione, Celeste. 2011. La gota que horada la piedra: Los migrantes en la prensa escrita argentina (1999-2007). Saarbrücken: Editorial Académica Española.

Courtis, Corina y Fernanda Longo Elía. 2000. La prensa como escenario del debate inmigratorio. Recuperado de: www.eca.usp.br (consultado 12 de julio de 2017).

Discepolo, Armando. [1925] 2006. Babilonia. Una hora entre criados. Buenos Aires: Galerna. 
Domenech, Eduardo (ed.). 2009. Migración y politica: el Estado interrogado. Procesos actuales en Argentina y Sudamérica. Córdoba: Universidad Nacional de Córdoba.

El Refaie, Elisabeth. 2001. "Metaphors we discriminate by: Naturalized themes in Austrian newspaper articles about asylum seekers". Journal of Sociolinguistics 5:3. 352-371.

Flax, Rocío. 2019. "La construcción del inmigrante en el discurso político argentino: el caso del Parque Indoamericano”. Revista D.E.L.T.A, 35:4. 1-20.

Flax, Rocío. 2020. Acerca de las dificultades de ser políticamente correcta: el discurso de Cristina Fernández sobre les migrantes. Revista Refracción, 1. 35-61

Fairclough, Norman. 1992. Discourse and Social Change. Cambridge: Polity Press.

Fairclough, Norman. 2000. "Representaciones del cambio en el discurso neoliberal". Cuadernos de relaciones laborales, 16. 13-35.

Fairclough, Norman. 2005. "Critical discourse analysis”. Marges linguistiques, 9. 76-94.

Fairlocugh, Norman. 2014. Language and Power. Third Edition. London: Routledge.

Grimson, Alejandro. 1999. Relatos de la diferencia y la igualdad. Los bolivianos en Buenos Aires. Buenos Aires: Eudeba.

Grimson, Alejandro. 2006. "Nuevas xenofobias, nuevas políticas étnicas en la Argentina”. En Migraciones regionales hacia la Argentina. Diferencia, desigualdad y derechos, ed. Por Alejandro Grimson, A y Elizabeth Jelin. Buenos Aires: Prometeo.

Hart, Christopher. 2010. Critical Discourse Analysis and Cognitive Science New Perspectives on Immigration Discourse. London: Palgrave, Macmillan.

Lakoff, George. 1987. Women, Fire and Dangerous Things. Chicago/London: University of Chicago Press.

Lakoff, George. 2002. Moral Politics. How Liberals and Conservatives Think. Chicago/London: The University of Chicago Press.

Lakoff, George. 2006. No pienses en un elefante. Madrid: Editorial Complutense.

Lakoff, George. 2010. "Why it Matters How We Frame the Environment". Environmental Communication, 4:1. 70-81.

Melella, Cecilia. 2015a. "Migraciones latinoamericanas y prensa gráfica. Análisis comparativo entre Argentina y España”. Odisea. Revista de Estudios Migratorios, 2. 157-183.

Melella, Cecilia. 2015b. "Prensa gráfica y migración sudamericana”. Estudios sociales contemporáneos, 13. 134-150.

Moliner, María. 2007. Diccionario del uso del español. Madrid: Gredos.

Novick, Susana (comp.). 2008. Las migraciones en América Latina. Políticas, culturas y estrategias. Buenos Aires: Catálogos-Clacso.

Oteiza, Enrique, Susana Novick y Roberto Aruj. 1997. Inmigración y discriminación. Políticas y Discursos. Buenos Aires: Grupo Editor Universitario.

Sarlo, Beatriz y Santiago Kalinowski. 2019. La lengua en disputa. Un debate sobre el lenguaje inclusivo. Buenos Aires: Ediciones Godot.

van Leeuwen, Theo. 2008. Discourse and Practice. New Tools for Critical Discourse Analysis. Oxford: Oxford University Press.

Wittgenstein, Ludwig. [1953] 1988. Investigaciones filosóficas. México: Instituto de Investigaciones Filosóficas UNAM.

Wodak, Rurth. 2003. "El enfoque histórico del discurso”. En Métodos del análisis crítico del discurso, Michael Meyer y Ruth Wodak (comps.), 101-141. Barcelona: Gedisa.

Lengua y migración / Language and Migration 12:2 (2020), 45-64

Edición impresa: ISSN 1889-5425. Edición en línea: ISSN 2660-7166. C Universidad de Alcalá 